\title{
Is breast cancer risk the same for all progestogens?
}

\author{
Petra Stute
}

Published online: 20 May 2014

(C) Springer-Verlag Berlin Heidelberg 2014

\begin{abstract}
Summary
The population-based case-control study CECILE investigated the impact of various menopausal hormone therapy (MHT) products on breast cancer (BC) risk in 1,555 postmenopausal women [1]. The case group $(n=739)$ included incident cases of in situ (!) or invasive BC in postmenopausal women. The control group $(n=816)$ included women from the general population within predefined quotas by age and socio-economic status (SES). While quotas by age were applied to obtain similar distributions by age among controls and among cases, quotas by SES in control women were applied to reflect the distribution by SES of women in the general population in the study area. Data of participants were obtained by a structured questionnaire during in-person interviews, and from pathology reports if applicable, respectively. Women were divided into current and past MHT user. MHTs were classified in estrogen-only therapy (ET), estrogen combined with progestin therapy (EPT) and tibolone. EPT was subdivided in three subtypes according to the progestogen constituent: natural micronized progesterone, progesterone derivatives, and testosterone derivatives. In comparison to never MHT users, any current or past MHT use (ET, EPT, tibolone) was not associated with an increased $\mathrm{BC}$ risk. However, in subanalysis $\mathrm{BC}$ risk was significantly increased for current use of EPT for 4 or more years $(n=73$ cases and $n=56$ controls, adjusted OR 1.55; $95 \%$ CI 1.02-2.36). Within the group of current EPT users for 4 or more years, 14 cases had used estrogens combined with micronized progesterone
\end{abstract}

\section{P. Stute $(\square)$}

Department of Obstetrics and Gynecology, University of Berne, Bern, Switzerland

e-mail: petra.stute@insel.ch
( $n=17$ controls), and 55 a combination with a synthetic progestogen ( $n=34$ controls), respectively. Compared to never MHT use, current use of EPT containing a synthetic progestogen for 4 or more years was associated with a significantly increased BC risk (adjusted OR 2.07; $95 \%$ CI 1.26-3.39), but EPT containing micronized progesterone was not (adjusted OR 0.79; $95 \%$ CI $0.37-1.71$ ). $73 \%$ of current MHT users started treatment within the first year of onset of menopause. Early EPT ( $n=52$ cases and $n=38$ controls, adjusted OR 1.65; $95 \%$ CI 1.02-2.69), but not early ET, starters had a significantly higher BC risk compared to never MHT users. In contrast, MHT initiation beyond 1 year after menopause was not associated with an increased BC risk. The authors concluded that: (1) ET and EPT containing natural progesterone did not increase BC risk whereas, (2) BC risk was increased in users of tibolone or EPT containing a synthetic progestogen, respectively, and that (3) MHT use early after onset of menopause was associated with an increased $\mathrm{BC}$ risk as compared to women who delay MHT beyond 1 or more years.

\section{Background}

The primary indication for MHT is vasomotor symptom control [2]. In women with an intact uterus systemic estrogens should be combined with a progestogen (natural progesterone or synthetic progestin) for endometrial protection. Since the initial report of the Women's Health Initiative in 2002 indicating an increased BC risk associated with the use of conjugated equine estrogens combined with medroxyprogesterone acetate (MPA) [3], there is a tremendous debate about whether all progestogens have the same negative impact on the postmenopausal mammary gland when combined with estrogens. Basically progestogens 
only have one effect in common, i.e., the progestogenic effect on the estrogen-primed endometrium [4]. Apart from that, there are large differences between progestogens with respect to other normal or malignant cells and tissues such as the mammary gland, respectively [5, 6]. So far there are four observational studies suggesting that the use of MHT containing progesterone or dydrogesterone, a stereoisomer of progesterone, is "safer" for the breast than using MHT containing synthetic progestins [7-10]. Of those, the prospective French E3N cohort study has been the largest trial to address $\mathrm{BC}$ risk with respect to progestogen type in combined MHT. Compared with MHT never use, BC risk was increased with MHT containing "other" progestogens (adjusted RR 1.69; $95 \%$ CI 1.50-1.91) but not with those containing progesterone (adjusted RR 1.00; $95 \% \mathrm{CI}$ $0.83-1.22$ ) or dydrogesterone (adjusted RR 1.16; $95 \%$ CI 0.94-1.43), respectively [9]. Similarly, a German case-control study only found an increased BC risk for use of norethindrone acetate containing MHT, for more than 5 years but not for other progestogens [11]. Long-term randomized placebo-controlled trials in humans investigating the impact of various combined MHT on the breast are lacking. However, in non-human primates a randomized crossover trial in ovariectomized cynomolgus macaques was performed comparing the impact of estradiol (E2), E2 combined with progesterone, E2 combined with MPA to placebo on breast epithelial proliferation [12] and mammary gene expression profiles [13]. Compared to placebo, E2 combined with MPA resulted in significantly greater breast proliferation in lobular and ductal epithelium, while E2 combined with progesterone did not [12]. Gene microarray analysis resulted in a greater number of significantly regulated genes for E2 combined with MPA when compared to E2 combined with progesterone and E2 alone with progesterone revealing greater antagonistic effects on E2-induced genes than MPA [13], which was supported by a small study in humans [14]. All these findings taken together suggest a more favorable effect for micronized progesterone and dydrogesterone on postmenopausal mammary gland.

\section{Comment}

The retrospective case-control study CECILE (LoE II2) picks up the current exciting subject on the impact of progestogen type on the mammary gland. At first sight, it supports previous findings from the prospective E3N study indicating that estrogens combined with micronized progesterone are "safer" for the postmenopausal mammary gland. However, a closer look reveals some limitations. First, the statistical analysis was based on small sample sizes. Indeed, the primary endpoint important for power calculation was not given and the authors themselves argued that the statistical power might have been limited for stratified analyses. Second, dosage and route of administration of progesterone were not assessed which might have an impact of BC incidence [6]. Next, cases included in situ and invasive $\mathrm{BC}$, and the authors did not present the respective absolute numbers. However, ductal carcinoma in situ (DCIS) is a non-obligate precursor of invasive BC with "only" $40 \%$ of these lesions progressing to invasive disease if untreated [15]. Therefore, the analysis should have been stratified with respect to in situ and invasive BC, respectively. Finally, there is a potential confounding by SES since control selection was based on SES within the population of the study area and not on BC cases.

Taken together the CECILE study serves as another hint indicating a favorable mammary profile for MHT containing progesterone. However, more evidence is needed. In respect to tibolone, the authors surprisingly commented on their results that "tibolone was also associated with an increased risk of BC" contradicting the Endocrine Society's statement that "tibolone reduces the risk of developing BC (LoEB)" [16]. In fact, absolute numbers for any duration of current ( $n=17$ cases, $n=8$ controls) and past tibolone users ( $n=10$ cases, $n=15$ controls) were very small. Statistical analysis did not reach significance at any time. Thus, interpretation should be more softened. Interestingly, the time gap between menopause and MHT initiation mattered which supports previous observations that delaying MHT onset for a certain, but yet undefined interval seems to be beneficial for the postmenopausal breast [17-19] which needs further investigation.

Conflict of interest None.

\section{References}

1. Cordina-Duverger E, Truong T, Anger A, Sanchez M, Arveux P, Kerbrat P, Guenel P (2013) Risk of breast cancer by type of menopausal hormone therapy: a case-control study among postmenopausal women in France. PLoS One 8:e78016. doi:10.1371/ journal.pone.0078016

2. North American Menopause S (2012) The 2012 hormone therapy position statement of: the North American Menopause Society. Menopause 19:257-271. doi:10.1097/gme.0b013e31824b970a

3. Rossouw JE, Anderson GL, Prentice RL, LaCroix AZ, Kooperberg C, Stefanick ML, Jackson RD, Beresford SA, Howard BV, Johnson KC, Kotchen JM, Ockene J, Writing Group for the Women's Health Initiative I (2002) Risks and benefits of estrogen plus progestin in healthy postmenopausal women: principal results from the Women's Health Initiative randomized controlled trial. JAMA 288:321-333

4. Schindler AE, Campagnoli C, Druckmann R, Huber J, Pasqualini JR, Schweppe KW, Thijssen JH (2003) Classification and pharmacology of progestins. Maturitas 46(Suppl 1):S7-S16

5. Ruan X, Seeger H, Mueck AO (2012) Breast cancer risk during hormone therapy: experimental versus clinical data. Minerva Endocrinol 37:59-74 
6. Kuhl H, Schneider HP (2013) Progesterone-promoter or inhibitor of breast cancer. Climacteric 16(Suppl 1):54-68. doi:10.3109/ 13697137.2013.768806

7. Lyytinen H, Pukkala E, Ylikorkala O (2009) Breast cancer risk in postmenopausal women using estradiol-progestogen therapy. Obstet Gynecol 113:65-73. doi:10.1097/AOG.0b013e31818e8cd6

8. de Lignieres B, de Vathaire F, Fournier S, Urbinelli R, Allaert F, Le MG, Kuttenn F (2002) Combined hormone replacement therapy and risk of breast cancer in a French cohort study of 3175 women. Climacteric 5:332-340

9. Fournier A, Berrino F, Clavel-Chapelon F (2008) Unequal risks for breast cancer associated with different hormone replacement therapies: results from the E3N cohort study. Breast Cancer Res Treat 107:103-111. doi:10.1007/s10549-007-9523-x

10. Schneider C, Jick SS, Meier CR (2009) Risk of gynecological cancers in users of estradiol/dydrogesterone or other HRT preparations. Climacteric 12:514-524. doi:10.3109/13697130903075352

11. Dinger JC, Heinemann LA, Mohner S, Thai do M, Assmann A, Assmann A (2006) Breast cancer risk associated with different HRT formulations: a register-based case-control study. BMC Womens Health 6:13. doi:10.1186/1472-6874-6-13

12. Wood CE, Register TC, Lees CJ, Chen H, Kimrey S, Cline JM (2007) Effects of estradiol with micronized progesterone or medroxyprogesterone acetate on risk markers for breast cancer in postmenopausal monkeys. Breast Cancer Res Treat 101:125-134. doi:10.1007/s10549-006-9276-y

13. Wood CE, Register TC, Cline JM (2009) Transcriptional profiles of progestogen effects in the postmenopausal breast. Breast Cancer Res Treat 114:233-242. doi:10.1007/s10549-008-0003-8

14. Murkes D, Lalitkumar PG, Leifland K, Lundstrom E, Soderqvist G (2012) Percutaneous estradiol/oral micronized progesterone has less-adverse effects and different gene regulations than oral conjugated equine estrogens/medroxyprogesterone acetate in the breasts of healthy women in vivo. Gynecol Endocrinol 28(Suppl 2):12-15. doi:10.3109/09513590.2012.706670

15. Cowell CF, Weigelt B, Sakr RA, Ng CK, Hicks J, King TA, Reis-Filho JS (2013) Progression from ductal carcinoma in situ to invasive breast cancer: revisited. Mol Oncol 7:859-869. doi:10.1016/j.molonc.2013.07.005

16. Santen RJ, Allred DC, Ardoin SP, Archer DF, Boyd N, Braunstein GD, Burger HG, Colditz GA, Davis SR, Gambacciani M, Gower BA, Henderson VW, Jarjour WN, Karas RH, Kleerekoper M, Lobo RA, Manson JE, Marsden J, Martin KA, Martin L, Pinkerton JV, Rubinow DR, Teede H, Thiboutot DM, Utian WH (2010) Postmenopausal hormone therapy: an endocrine society scientific statement. J Clin Endocrinol Metab 95:s1-s66. doi:10.1210 /jc.2009-2509

17. Prentice RL, Chlebowski RT, Stefanick ML, Manson JE, Pettinger M, Hendrix SL, Hubbell FA, Kooperberg C, Kuller LH, Lane DS, McTiernan A, Jo O'Sullivan M, Rossouw JE, Anderson GL (2008) Estrogen plus progestin therapy and breast cancer in recently postmenopausal women. Am J Epidemiol 167:12071216. doi:10.1093/aje/kwn044

18. Fournier A, Mesrine S, Boutron-Ruault MC, Clavel-Chapelon F (2009) Estrogen-progestagen menopausal hormone therapy and breast cancer: does delay from menopause onset to treatment initiation influence risks? J Clin Oncol 27:5138-5143. doi:10.1200/ JCO.2008.21.6432

19. Beral V, Reeves G, Bull D, Green J, Million Women Study C (2011) Breast cancer risk in relation to the interval between menopause and starting hormone therapy. J Natl Cancer Inst 103:296-305. doi:10.1093/jnci/djq527 